\title{
Using Bloom's Taxonomy to Evaluate the Cognitive Levels of Master Class Textbook's Questions
}

\author{
Ibtihal R. Assaly ${ }^{1} \&$ Oqlah M. Smadi ${ }^{2}$ \\ ${ }^{1}$ The English Department, Al-Qasemi Academy_Academic College of Education Baqa al-Gharbiyye, Israel \\ ${ }^{2}$ Department of Curriculum and Instruction, Yarmouk University, Irbid, Jordan \\ Correspondence: Ibtihal Assaly, The Department of English, Al-Qasemi Academy-Academic College of \\ Education, Baqa al-Gharbiyye, Kfar Qari', 3007500, POB 1200, Israel. Tel: 972-502-208-455. E-mail: \\ ibtassaly@hotmail.com
}

Received: January 22, 2015 Accepted: March 12, 2015 Online Published: April 23, 2015

doi:10.5539/elt.v8n5p100 URL: http://dx.doi.org/10.5539/elt.v8n5p100

\begin{abstract}
This study aimed at evaluating the cognitive levels of the questions following the reading texts of Master Class textbook. A checklist based on Bloom's Taxonomy was the instrument used to categorize the cognitive levels of these questions. The researchers used proper statistics to rank the cognitive levels of the comprehension questions. The results showed that the author of Master Class emphasized the cognitive level of Comprehension having $52 \%$ of the questions, which was much more than the expected frequency, while wrote only $3.7 \%$ and $6 \%$ of the questions on the cognitive levels of Knowledge and Application respectively. The frequency of questions on the cognitive levels of Evaluation and Analysis were much closer to the expected frequencies. The results indicated that about $40 \%$ of the textbook's questions emphasized higher-order thinking skills, which goes with the requirements of the revised curriculum. Evaluating and choosing a good textbook that goes with the goals of the curriculum is recommended. Such a study would shed light upon the role of textbooks in developing cognitive skills among Arab students.
\end{abstract}

Keywords: Bloom's taxonomy, questions, revised curriculum, textbooks' analysis

\section{Introduction}

Knowledge, as an outcome of education, is no longer believed to be sufficient to create the kind of citizens needed to effectively cope with the social, economical and technological changes in the world. In the last few decades, there has been an intense call to raise the level of educational achievements. In contrast with the previous generations, Wagner (2008, p. 21) asserts that the global information economy now requires greater breadth and depth of skills in making meaning. Students accordingly "need to master seven survival skills: critical thinking and problem solving, collaboration and leadership..., effective oral and written communication, accessing and analyzing information, curiosity and imagination." Shavinia (cited in Yamin, 2013) claims that citizens who think critically and creatively are "guarantees of political stability, economic growth, scientific and cultural enrichment, psychological health, and the general prosperity of any society in the $21^{\text {st }}$ century" (abstract). As a result, more attention has been given all over the world to the importance of developing students' HOTS (Gallaghera, Rosemary, \& Zohar, 2012; Lin, 2005; Yamin, 2013; Zohar, 2007).

Many nations have become more concerned with the incorporation of the cognitive skills within their national curricula (Craft, 2005; Shaheen, 2010; Gallagher et al., 2012). Curriculum reforms have been carried out and higher-order thinking skills (HOTS) have been included in educational policies in many countries (Shaheen, 2010; Lin, 2011). "Like other countries, [in 2007], Israel has had its share of projects that see the implementation of inquiry and higher order thinking in schools as their main goal" (Gallagher et al., 2012, p. 139). These projects aim at enabling students to grasp a deep understanding of what they are learning and be more critical and creative instead of merely recalling information.

\subsection{Infusing HOTS in the English Curriculum}

Since the English language can play a vital role in enabling students to function successfully in this highly technical society and fast-paced change in the world, the English Curriculum Committee's and the English Inspectorate decided to infuse HOTS to English teaching through teaching literature. Accordingly, since 2008, 
high school teachers have been required to teach a number of literary pieces (short stories, articles, poems, plays and novels) while infusing and emphasizing the following six thinking skills: comparing and contrasting; distinguishing different perspectives; explaining cause and effect; explaining patterns; inferring; and problem solving. Therefore, teachers must explicitly teach thinking skills through focused instruction and ask the right instructional questions about the literary texts taught to enhance students' thinking.

Though it is easier to teach HOTS while teaching literature, it is not enough to concentrate on these skills only when teaching literary texts. HOTS should be emphasized while teaching any kind of texts to improve understanding.

Reading comprehension is the core of the teaching/learning process in all disciplines. Students cannot understand history, biology, social science or math if they do not read proficiently and critically. As a result, textbooks must emphasize reading comprehension strategies and guide students to read critically while reading in the language lessons. When students acquire these skills by practicing them on various texts, they will be able to transfer them while reading in different disciplines and later while reading outside the school scope, which is the main goal of teaching HOTS. Sidek (2010, p. 83) asserts that "secondary students may not be prepared for the more difficult cognitive demands of reading tasks in EFL at the tertiary level" if they are only exposed to reading tasks that require low cognitive demands. Enabulele $(2011$, p. 7), on the other hand, claims that "students who are proficient in reading have a greater chance of success in the job market."

\subsection{How Are the Levels of Comprehension Developed?}

Reading is the basic means to get knowledge. Unfortunately, however, while reading, many students focus more on word accuracy rather than comprehension and in most cases they can only understand what they read at the literal level. They can infer what the words say superficially but find it difficult to read between the lines to get the underlying meaning and intentions of the writer (Fisher, 2005). These readers "possess inefficient reading strategies and use them inflexibly. .... [They, accordingly,] need to be shown how and when to apply a small repertoire of comprehension strategies" (Department of Education and Training, 2010, p. 2). In order to provide the students with a richer, meaningful reading experience, they have to be moved from the literal or concrete level of thinking to higher levels in which they do something with the facts they get from the texts they read (Curriculum Associates).

The thinking process that is operated by students is essential for mental health, high achievements, and professional success. As a result, students should be encouraged to give opinions about what they read, to analyze materials, to form creative ideas, to evaluate, to compare and contrast different choices and to relate what they read with their own experiences. With sufficient explicit instruction of the reading strategies, noticeable gains in comprehension will be achieved by students. When the students get to the level in which they use the reading strategies simultaneously, they will know when to apply each strategy while reading any text, and only then they "can read a variety of materials with ease and interest, can read for varying purposes, and can read with comprehension even when the material is neither easy to understand nor intrinsically interesting" (Snow, 2002, p. xiii).

Acquiring these strategies is crucial for students' success in all disciplines. Several taxonomies have been proposed as a result of numerous studies in the area of questions and objectives, such as those proposed by Guilford, Weaver, and Bloom. These taxonomies embody the levels of three educational objectives by which activities are posed - cognitive, psychomotor, and affective. The cognitive taxonomy, which was proposed by Bloom (1956), is the most commonly used in the area of education. Krathwohl (2002) states that

Bloom saw the original Taxonomy as more than a measurement tool. He believed it could serve as means for determining the congruence of educational objectives, activities, and assessments in a unit, course, or curriculum; and panorama of the range of educational possibilities against which the limited breadth and depth of any particular educational course or curriculum could be contrasted" (p. 212).

The six levels within the cognitive domain are divided into two levels of thinking skills:

- Lower-Order Thinking Skills (LOTS): Knowledge, Comprehension and Application

- Higher-Order Thinking Skills (HOTS): Analysis, Synthesis and Evaluation. (Bloom, Englehart, Furst, Hill, \& Krathwohl, 1956; Truschel, 2010)

Many researchers who have studied how levels of comprehension affect reading comprehension have taken Bloom's Cognitive Taxonomy as a frame for their work. Curriculum designers, book writers and teachers also consider using it as a "tool to ensure appropriate coverage of a variety of types of cognitive demands made on 
students [with a] range of learning processes [that extend] from the common lower tasks to include higher level cognition" (Surjosuseno \& Watts, 1999, p. 7).

\subsection{The Role of English Textbooks in Developing Students' Higher-Order Thinking Skills}

It is widely acknowledged that textbooks exert a powerful and precious influence on education. English language textbooks, however, evoke different responses among English teachers. Some believe they are "masses of rubbish skillfully marketed" (Brumfit, cited in Sheldon, 1988, p. 237) and prefer not to use them, while others consider them "necessary evils" (Sheldon, 1988, p. 237), which because of the "sheer labor-intensiveness of developing classroom materials, the pressures of heavy timetable, and the highly restrictive nature of most teaching situations, [they find themselves forced to] choose a book which only approximates to the needs of the local context" (Sheldon, 1988, p. 238).

Their choice is usually done in haste, having no systematic applied criteria. This makes them unhappy about their compromise and, accordingly, find themselves, instead of dealing with the textbook as a route map for the whole course, go in the maze of choosing the parts from the textbook that adequately fulfill their teaching objectives, modifying the parts that do not suit their students well, and bringing teacher-generated materials that help in imposing the components they feel the textbook lacks.

One of the basic components of textbooks is the text. Shulman (1987, p. 15) asserts that "[t]hough most teaching begins with some sort of text, and the learning of that text can be worthy end in itself, we should not lose sight of the fact that the text is often vehicle for achieving other educational purposes." In order to help students achieve the educational purposes intended, questions, which are the second basic component of the textbooks, are needed. Good questions and well-built activities that follow each text in a textbook should be written in a way that helps attaining the educational objectives and lead students to think critically.

Research has revealed that "higher order questions may have a somewhat broader general facilitative effect than factual adjunct questions" (Hamaker, 1986, p. 237). Andre (1987, p. 81) also claims that "higher level adjunct questions facilitate the learning of factual information from text and increase the amount of attention readers devote to processing text." Besides, Armbruster and Ostertag (1989, p. 3) state that when students are asked questions on a certain text they "form expectations based on the type of question they receive, and these expectations affect learning from reading subsequent material. ...[S]tudents' interaction with questions directly influences future learning outcomes." This emphasizes the role questions play to promote higher order processing of the text.

English textbooks are usually full of questions that come either at the beginning or at the end of each section, lesson or chapter; unfortunately however, research has shown that most textbooks do not contain materials, nor do they include questions that require critical thinking and meta-cognitive processes (Collins, Brown, \& Newman, 1989). Most textbooks questions, as research indicates, emphasize the lower-order cognitive levels (Cotton, 1991; Ighbaria, 2013; Riazi \& Mosalaejad, 2010). Accordingly, the cognitive levels of the textbook questions should be one of basic criteria to be used to evaluate textbooks.

The situation in Israel is similar to the situation in some other countries where there is no fixed textbook from the Ministry of Education for each level in the whole country. Teachers usually have a variety of textbooks approved by the Ministry of Education published by two main publishing companies for each grade and proficiency level. The teachers in each school consequently choose a textbook either because it is highly recommended by one of the publishing companies, or because other teachers recommend it.

Many English teachers do not thoroughly evaluate the textbook they choose to adopt, either because they feel it is tiring and time-consuming process, or because, in many cases, they are not qualified enough to do so. They do not have the competence and the experience to evaluate a book before using it. They claim that the textbook is only a tool or a teaching aid that they can manipulate to serve their educational and learning objectives.

By doing so, however, they ignore the fact that textbook evaluation either before, while or after using the textbook, helps teachers in their personal and professional development. It is, as Hutchinson (1987, p. 38) says, "a two-way process which enables teachers not just to select a textbook, but also to develop their awareness of their own teaching/ learning situation." It makes teachers acquire and develop understanding regarding the nature of textbook material in a general manner, rather than impressionistic assessment. It helps them choose the textbook that is compatible with their teaching objectives, and suits the level and needs of their students, which ultimately ensures high quality teaching.

As a result, the researcher saw it important to analyze one of the textbooks used to teach English for high proficiency level students to find out to what extent the recent trend of developing students' HOTS was reflected 
in the questioning practices of the textbooks, and accordingly help teachers choose the textbooks that adequately facilitate the teaching process and prepare students for high cognitive demands of reading tasks in EFL at the tertiary level.

\subsection{Review of Related Studies}

A number of studies have been conducted to investigate the type and the cognitive level of the textbooks' questions in different subjects and different countries around the world using Bloom's taxonomy as a guide for categorizing the questions.

Karns, Burton, and Martin (1993), for example, studied six principles of economic texts and the instructor's manuals that accompanied them using content analysis. The aim of their study was to determine if the questions contained in the instructor's manual really measured the level of achievement of stated course objectives.

The results revealed that though most authors placed few learning objectives on the first three levels of knowledge, comprehension and application, the questions on these three levels were significantly given more importance. On the other hand, the other three levels, which related to the higher-order thinking levels in Bloom's Taxonomy, were not addressed as a learning level neither as objectives nor as questions by most the texts' authors. Even when listed as part of the learning objectives, the authors failed to provide questions on them.

Ibrahim (1998) analyzed $6^{\text {th }}$-grade history book questions according to the cognitive domain in Bloom's taxonomy in Iraq. Out of the 87 questions that he found in the book, $72 \%$ of the questions were asked at the cognitive level of knowledge. $25.4 \%$ of the total of the questions were asked at the comprehension level and the evaluation questions received $2.2 \%$, the three other levels - application, analysis and synthesis scored $0 \%$.

Riazi and Mosalaejad (2010) investigated which levels of Bloom's taxonomy were more focused on in Iranian high school and pre-university textbooks. They evaluated three senior high school and one pre-university textbooks using Bloom's taxonomy.The results obtained showed that the lower-order cognitive skills were more dominant having learning objectives on comprehension, application and knowledge more frequently. Objectives on the level of evaluation were the least in the four English textbooks. Analysis and synthesis came in between in all the books.

Razmjoo and Kazempourfard (2012) analyzed the activities and the exercises for three units of each of the four coursebooks of the Interchange series using the six levels of Bloom's Revised Taxonomy. The researchers utilized a coding scheme to codify, classify and analyze the exercises and activities of the coursebooks. The results showed that lower order cognitive skills were most frequent in Interchange coursebooks. Remembering, which is the lowest cell in Bloom's Revised Taxonomy, was the most frequent code followed by applying in the four books. Understanding metacognitive knowledge and evaluating cognitive knowledge were found to have the least frequent codes with $0 \%$ of distribution.

Ighbaria (2013) analyzed the six units of the 9th grade English textbook Horizons. His main objective of the study was to assess the importance of textbooks in developing students' thinking. He chose the WH-questions as the unit for analysis believing that questions are important for examining students' understanding for the taught material, and that through questions, students' thinking skills can be developed. The results revealed that out of the $381 \mathrm{WH}$-questions that the six units included, the percentages ranged from $29.66 \%-2.36 \%$ which related to the cognitive levels of comprehension and evaluation respectively. These results confirm the results that appeared in previous studies. The outstanding finding was that the analysis level appeared at a percentage of $23.36 \%$, which is nearly equivalent to the knowledge level.

\subsection{Statement of the Problem}

Textbooks writers and publishing companies are working on writing new textbooks that meet the objectives of the revised curriculum. No new textbook, however, has currently been published for high school that meets these requirements, accordingly high school teachers are still using textbooks published at least six years ago. The problem that English teachers face is that there are several books for each level offered by the different publishing companies that are approved by the Ministry of Education. Teachers have difficulty choosing the book suitable for each level, which adequately fulfills the goals set by the curriculum, and, in the same time, helps them in developing students' thinking levels.

The researcher chose Master Class textbook, which is written for proficiency level, stage one students, to investigate the cognitive levels of the questions in the Mastering Reading sections in order to find out the extent to which they lead students towards levels that demand higher thinking skills as the revised curriculum entails. 
Accordingly, the study addresses the following question:

- What are the cognitive levels of the questions that follow the reading texts in Master Class textbook?

\subsection{Significance of the Study}

The researchers think that this study is the second of its kind that investigates the cognitive level of the questions in high school English textbooks in Israel. Several studies were conducted in the last few decades to examine the type and cognitive levels of the questions that appear in textbooks in different countries and in different subjects (Armbruster \& Ostertag, 1989; Hampton, Krentler, \& Martin, 1993; Ibrahim, 1998; Karns, Burton, \& Martin, 1993), while very few studies dealt with the type and the cognitive level of the questions given in English textbooks (Razmjoo \& Kazempourfard, 2012; Riaz \& Mosalaejad, 2010). Only one study, Ighbaria (2013), investigated the type and the cognitive level of the questions in the textbooks used in Israel. In consistence with all the other studies, the results of the last study revealed that the authors of the textbooks tended to emphasize lower cognitive levels in the textbook questions.

The results of this study will therefore contribute to all those involved in the educational practice of English teaching in Israel, the textbook authors as well as the Ministry of Education. The results of the study will also raise their awareness of the cognitive levels of the questions included in these textbooks. In addition, the results will alert teachers to the importance of evaluating the textbooks offered by publishing companies in order to choose the ones that better help them achieve the curriculum objectives. Otherwise, they must modify their practices and materials in a way that makes them achieve higher levels of teaching/learning objectives.

\subsection{Definitions of Relevant Terms}

Questions are any of the following: a Wh-question, a Yes/No question, a Multiple Choice question, Complete the sentence or the Chart, a Statement question, a Request question, or an activity.

Master Class textbook. Master Class is a course book for the tenth grade high school students at Proficiency Level, Stage 1. It was written by Edna Assis and was published in 2008 by Eric Cohen Books Ltd. Master Class is divided into seven sections; two Mastering Reading sections, two Mastering words sections, one Mastering Language section, one Mastering Listening section and one Mastering Writing section. The Mastering Reading sections include different kinds of texts (interview, article, newspaper editorial, personal account, review, website and timeline), preceded and followed by several types of reading comprehension questions.

\section{Methodology}

\subsection{Instrument of the Study}

For the purpose of this study a checklist was used to record and tally the cognitive levels of the questions collected from the Mastering Reading sections of Master Class textbook.

The researchers built a checklist based on Bloom's Taxonomy of the cognitive domain. The checklist is composed of a table with eight columns. The first column contained the serial number of the question; the second contained the question, while each of the following six columns contained one of the six cognitive levels of Bloom's Taxonomy placed in sequence from low to high.

The checklist was combined with explanatory sheets that contained two tables: a table in which a definition for each of the six cognitive levels and examples on the verbs used for each level, and a table with example questions and activities on each level. The tables were added to make it easier for the researchers decide the cognitive level of each question coded.

\subsubsection{Validity of the Checklist}

Bloom's taxonomy was used and determined to be valid in various previous studies (Ighbaria, 2013; Razmjoo \& Kazempourfard, 2012; Riazi \& Mosalaejad, 2010). It was also accepted among the educational community as a means of categorizing and "determining the congruence of educational objectives, activities, and assessments in a unit" Krathwohl (2002, p. 212). Accordingly, the checklist, being directly derived from Bloom's Taxonomy, was considered valid.

To further validate the checklist, its concepts were first defined accurately, depending on the definitions given in the literature about Blooms taxonomy. The checklist was displayed to a panel of five experts to examine the definitions of the levels according to the skills and questions demonstrated for each level. There was a consensus among them regarding these categories and the definitions. The instrument also appeared appropriate for the study. 


\subsubsection{Reliability of the Checklist}

\section{Inter-Rater Reliability}

Reliability of the checklist depends on the raters' utilization of the instrument. In order to establish reliability of the checklist, the researchers collected, coded and categorized all the questions following the reading texts of the first and the second units of another textbook called Results for 4 points.

Using Holsti's equation to calculate the reliability coefficient (Holsti, 1969), the researchers found that the agreement coefficient was $91.3 \%$.

\subsection{Data Collection}

The researchers obtained two copies of Master Class textbook. Each used the the book separately to code the questions depending on the instructions given earlier.

The first results of coding the questions were identical: both the researcher and the second analyst found 135 questions. The questions were then categorized according to Bloom's Taxonomy using the checklist.

\subsection{Data Analysis}

To analyze the cognitive level of the questions of the reading comprehension sections in Master Class textbook multiple steps were used.

From the coded questions taken from the textbook, the frequencies for each level of cognition in each unit were firstcalculated. The totals for each cognitive level in the six units were summed to derive a total for each level of cognition. The total for each level was divided by the grand total of the questions in the six units to arrive at the percentage for each cognitive level within the six units. Chi-square goodness-of-fit test was then used. The expected frequency and the residual for each thinking skill were calculated, and then the standardized residual was computed. The aim was to rank the cognitive levels of the reading comprehension questions according to their frequencies.

\section{Results and Interpretations}

Table 1 presents the cognitive levels of the reading comprehension questions according to their standardized residual values in a descending order.

Table 1. Frequencies, percentages and chi-square goodness-of-fit values for the cognitive levels of the questions arranged in a descending order according to the standardized residual values

\begin{tabular}{|c|c|c|c|c|c|c|c|c|c|c|}
\hline Rank & $\begin{array}{l}\text { Level } \\
\text { ID }\end{array}$ & Question & $\begin{array}{l}\text { Observed } \\
\mathrm{N}\end{array}$ & $\%$ & $\begin{array}{l}\text { Expected } \\
\mathrm{N}\end{array}$ & Residual & $\chi^{2}$ & $\mathrm{df}$ & Sig. & $\begin{array}{l}\text { Standardized } \\
\text { Residual }\end{array}$ \\
\hline 1 & 2 & Comprehension & 70 & 51.8 & 22.5 & 47.5 & 100.278 & 1 & 0.000 & 10.014 \\
\hline 2 & 6 & Evaluation & 21 & 15.5 & 22.5 & -1.5 & 0.100 & 1 & 0.752 & -0.316 \\
\hline 3 & 4 & Analysis & 20 & 14.8 & 22.5 & -2.5 & 0.278 & 1 & 0.598 & -0.527 \\
\hline 4 & 5 & Synthesis & 11 & 8.1 & 22.5 & -11.5 & 5.878 & 1 & 0.015 & -2.424 \\
\hline 5 & 1 & Knowledge & 8 & 5.9 & 22.5 & -14.5 & 9.344 & 1 & 0.002 & -3.057 \\
\hline 6 & 3 & Application & 5 & 3.7 & 22.5 & -17.5 & 13.611 & 1 & 0.000 & -3.689 \\
\hline Total & & & 135 & 100 & 135 & 0 & 129.489 & 5 & 0.000 & 0 \\
\hline
\end{tabular}

Table 1 shows that the total number of the questions that were categorized according to Bloom's Taxonomy was 135. The frequencies of the questions of the six cognitive levels range from 5-70, while the percentages range from $3.7 \%$ for the cognitive level of application to $51.9 \%$ for the comprehension level. The standardized residual values indicate that the observed frequency of the questions on the comprehension level is significantly higher than the expected frequency for that level.

The thinking skill that appears most frequently after comprehension is evaluation with 21 questions (15.6\%) which is the same as that of the expected frequency for these questions according to the standardize residual value. Analysis comes third with 20 questions (14.8\%). This number also approximately equals the number of the expected frequency for this skill. The fourth skill is synthesis with 11 questions $(8.1 \%)$. The number of questions on this skill is significantly lower than the expected frequency of these questions. There are 8 
questions (5.9\%) of knowledge, and 5 questions (3.7\%) of application. The standardized residual values for these two skills indicate that the expected frequencies of the questions for both skills are significantly higher than the observed frequencies.

These results show that Master Class textbook is successful in adopting the two higher thinking skills of evaluation and Analysis. There is shortage, however, in the number of the synthesis questions, the third higher thinking skill. On the other hand, the number of questions on the cognitive level of comprehension is too high.

\section{Discussion, Conclusions and Recommendations}

\subsection{Discussion}

Scholars who examined the effect of the questions on foreign language learning indicated that the level of the cognitive demand of language tasks is an important factor in language mastery (e.g., Igbaria, 2013; Lin, 2009, 2010; Sidek, 2010). In order to achieve the required information needed for academic success and for life, the cognitive demands of the reading tasks given for students should be of various levels. More emphasis, however, should be put on tasks that need high cognitive demands (Ministry of Education, 2011; Zohar, 2008).

The results showed that Master Class textbook included reading comprehension questions that required both lower level and higher level cognitive demands. They, however, showed that the cognitive levels of the questions were not fairly varied. First, $40 \%$ of the questions in Master Class needed HOTS while $60 \%$ needed lower-order thinking kills (LOTS). Second, while there were knowledge and application questions, they were relatively few when compared with the frequency of comprehension questions. There were, for example, 70 comprehension questions, while there were only five application questions.

Having more LOTS than HOTS questions should not affect the judgment on the textbook for several reasons. First, Bloom (1956) emphasized the importance of offering lower level information to students as a basis to move to upper levels of cognition. Armbruster and Ostertag (1989, p. 2) also claimed that "no one suggests that all questions should be high level". They added that "the use of factual questions can be defended on the grounds that students need to know certain basic information before they can engage in higher order thinking".

Second, taking a closer look at the number and the nature of the questions that require lower-order thinking skills, the researchers believe that the author of the textbook was successful in her choices. The cognitive level of knowledge appears only $5.9 \%$ of the time in all the units. This result contradicts with the results of most of the previous studies (Igbaria, 2013; Razmjoo \& Kazempourfardm, 2012; Riazi \& Mosalaejad, 2010), in which more questions or even most of the questions in the textbooks were of the knowledge type.

Moreover, other than having only eight Knowledge questions out of the 135 questions, which is a positive change, such questions are presented in a way that requires the students to think and interact, and not just to recall information. On page 84, for instance, there is the following question," You are going to read a review of a movie about global warming. Share what you know about the subject with the class. The following words from the review may help you." On page 92, there is another question that asks students to recall information they know about different topics, yet the question asks them to recall the information by asking them to expect what they will find when they click on several internet links, so it connects them with technology.

The application cognitive level received the lowest percentage in the textbook analysis having only five questions/activities (3.7\%) in the twelve reading sections of the textbook. These results also contradict with some of the results of the previous studies (Karns et al., 1993; Razmjoo \& Kazempourfard, 2012; Riazi \& Mosalaejad, 2010), where the application questions appeared more frequently.

The researchers believe that this number of questions is considered logical in these sections since they focus on receptive and not on productive skills, the access to information domain and not the presentation domain. Questions that belong to the cognitive level of application are expected more in sections like Mastering language or Mastering Writing.

The third cognitive level related to the lower-order thinking skills is comprehension. The results show that there are $70(51.8 \%)$ comprehension questions. Having such a high frequency of these questions is also quite reasonable in this study as the data were collected from sections that focused mainly on the domain of access to information and where the questions in these sections should emphasize students' comprehension.

There is no doubt that the author of Master Class tried to expose students to different types of questions to make the texts more comprehensible. There are, for example, several Wh-questions like "Why do supertasters taste things more intensely than other people? (line 19)"; Yes/ No questions as "Choose the correct answer Yes or No. Most people continued to use black and white film long after the invention of color film. Yes/ No," and Requests 
"Name two other results of global warming according to lines 49-60", to mention just a few. The textbook also contains several activities in which the students are asked to work alone, in pairs or in groups to do diverse tasks.

However, instead of having questions that needed higher levels of processing, the textbook author, presented questions that need in most cases short and direct answers. Most of her questions were 'Display' or 'close-ended' questions which have only one right response that could easily be detected from the text.

An example of such questions is: "What are two advantages of being a Super taster?

a) Supertaster do not usually because they

b) They also do not usually because they ." (p. 17)

In fact, there are some 'open-ended' questions, yet the kind of questions that she wrote did not need "complex inferences, such as pulling together information from several locations in the text," (Armbruster \& Ostertag, 1989 , p. 8), which require higher cognitive demands. There is, for instance, this question on page 86, "Name two other results of global warming, according to lines 49-60", and on page 109, we have this question: "The Navajo language was difficult for non-Navajos to learn. Give ONE reason of this. (lines 15-19)." The answers for these questions are easily detected from the text.

The third reason for which the judgment of the textbook should not be negatively affected by the results is the frequency of the questions that required the higher cognitive levels. The number of the questions that required the cognitive levels of analysis and evaluation is comparatively high. They appeared at the frequency of 21 and 20 and the percentages of $15.5 \%$ and $14.8 \%$ respectively, which is quite a good percentage not only compared with the results of the previous studies but also with the kind of questions that are usually asked after any reading comprehension text in a foreign language where the main goal is usually comprehension and not developing thinking skills. There is, for example, an analysis question on page 45, "Which of the following words describe how you felt as you read this editorial? Explain," As for the evaluation level, we can see the following question "Imagine that you've been in a Europeans city and wanted to buy a newspaper, but there is no one to take the money - just an "honesty box" to put it in. Would you pay for the newspaper or not?" and on page 26, "Yair advises parents to keep track of their kids. What do you think of his advice? Should parents check up on their teenagers? “

Synthesis questions appeard at a frequency of 11 and a percentage of $8.1 \%$. In congruence with Ighbaria's (2013) and Sidek's (2010) studies, the results show that the frequency of these questions is relatively high compared to the frequency of knowledge and application questions together. An example of the synthesis questions is on page 52 , "What was the writer's purpose in writing this editorial?"

Accordingly, the researchers believe that the number of the questions that required HOTS in the textbook is quite acceptable when compared with the results of Igbaria's (2013) and Riazi and Mosalaejad's (2010) studies, in which more emphasis were on questions that needed LOTS.

\subsection{Conclusions}

1) Master Class textbook incorporated reading comprehension questions that require both the lower level and the higher level cognitive demands. The textbook author, however, was not successful in varying the cognitive levels of the reading comprehension questions, where she exaggerated in presenting comprehension questions and nearly neglected application questions.

2) The rising number of the questions that require high cognitive demands in the textbook suggests that the author considered the importance of training students on these levels of questions, which will eventually contribute to an effective EFL reading content especially at the university level or even for daily life needs.

3) In line with EFL revised curriculum requirements, the textbook author succeeded in increasing the number of questions that require HOTS.

\subsection{Recommendations}

There is no doubt that the results of the study are encouraging. However, the English teachers and book authors have to take the following limitations of the study into consideration: the researchers analyzed Master Class textbook only, which is one of the textbooks intended for high proficiency level school students. Moreover, the study used Bloom's taxonomy for analyzing the cognitive levels of the questions in the textbook Master Class.

Accordingly the following recommendations are proposed by the researchers:

1) Teachers have to evaluate any textbook before using it. The textbook should suit the students' proficiency and cognitive level and meets the goals of the curriculum. 
2) A good textbook can be an important agent to implement the change in the curriculum, but it cannot work alone. The teacher should decide what to take from the textbook and what to add by using other sources. They should also prepare well in order to direct the textbook content in a way that serves his/her goals and not vice versa.

3) English textbooks should include reading tasks of various cognitive demands in order to equip students with the ability to perform tasks at any cognitive level in English at the school and university level.

4) Textbooks authors should be aware of the different cognitive levels of the students in each grade level, they should accordingly use texts that respond to the students needs and present questions that encourage them to think and participate.

5) Textbook authors should take the changes in the curriculum into consideration when writing new textbooks.

\section{References}

Al-Khataibeh, S., \& Al-Hameed, A. (2002). An analysis of history questions in the secondary general exam in Jordan according to Bloom's taxonomy of cognitive domain (M.A. Thesis). Irbid, Jordan: Yarmouk University.

Andre, T. (1979). Does answering higher-level questions while reading facilitate productive learning? Review of Educational Research, 49, 280-318. http://dx.doi.org/10.3102/00346543049002280

Armbruster, B. B., \& Ostertag, J. (1989). Questions in elementary science and social studies textbooks. Center for the Study of Reading. Champaign, Illinois: University of Illinois at Urbana-Champaign. http://hdl.handle.net/2142/17741

Bloom, B. (1984). Taxonomy of educational objectives, book 1: Cognitive domain. New York: Longman.

Bloom, B., Englehart, M., Furst, E., Hill, W., \& Krathwohl, D. (1956). Taxonomy of Educational Objectives: The Classification of Educational Goals. Handbook I: Cognitive domain. New York: Longman.

Bull, S. G. (1973). The role of questions in maintaining attention to textual material. Review of Educational Research, 43, 83-88. http://dx.doi.org/10.3102/00346543043001083

Collins, A., Brown, J. S., \& Newman, S. E. (1989). Cognitive apprenticeship: Teaching the crafts of reading, writing, and mathematics. In L. B. Resnick (Ed.), Knowing, learning and Instruction: Essays in honour of Robert Gla-ser (pp. 453-494). Hillsdale, NJ: LEA.

Cotton, K. (1991). Teaching thinking skills. Northwest Regional Educational Laboratory. Close up \# 11. Retrieved from http://hppa.spps.org/uploads /teachingthinking skills.pdf

Craft, A. (2005). Creativity in Schools: Tensions and Dilemmas. Rutledge, London.

Creswell, J. (2012). Educational Research: Planning, Conducting, and Evaluating Qualitative and Quantitative Research. Fourth edition. Pearson.

Curriculum Associates. Research paper: Building levels of comprehension: Retrieved from http://www.casamples.com/downloads/blc-research.pdf

Department of Education and Training. (2010). Teaching Comprehension Strategies. Curriculum K-12.

Enabulele, A. (2011). A Critical thinking in secondary language arts: Teacher perception and relevant strategies (M.A. Thesis). Eric.

Fisher, R. (2005). Teaching Children to Think. Cheltenham: Nelson.

Gallagher, C., Hipkins, R., \& Zohar, A. (2012). Positioning thinking within the national curriculum and assessment systems: Perspectives from Israel, New Zealand and Northern Ireland. Thinking Skills and Creativity, 7, 134-143. http://dx.doi.org/10.1016/j.tsc.2012.04.005

Hamaker, C. (1986). The effects of adjunct questions on prose learning. Review of Educational Research, 56(2), 212-242. http://dx.doi.org/10.3102/00346543056002212

Hampton, D., Krentler, K., \& Martin, A. (1993). The use of management and marketing textbook multiple-choice questions: A case study. Journal of Education for Business, 69(1), 40-43. http://dx.doi.org/10.1080/08832323.1993.10117654

Holsti, O. R. (1969). Content Analysis for the Social Sciences and Humanities. USA: Addison Wesley Publishing Company. 
Hutchinson, T. (1987). What's Underneath?: An interactive view of materials evaluation. In L. E. Sheldon (Ed.), ELT Textbooks and Materials: Problems in Evaluation and Development. ELT document 126. London. Modern English Publication in Association with the British Council.

Ibrahim, F. (1998). Curricula foundations, organizations, and Evaluation. Cairo: Egypt Library.

Igbaria, A. (2013). A Content analysis of the WH-questions in the EFL textbook of Horizons. International Educational Studies, 6(7), 200-224. http://dx.doi.org/10.3102/00346543049002280

Karns, J., Burton, G., \& Martin, G. (1983). Learning objectives and testing: An analysis of six principles of economic textbooks using Bloom's taxonomy. Journal of Economic Education, 14(3), 16-20. http://dx.doi.org/10.1080/00220485.1983.10845021

Krathwohl, D. R. (2002). A revision of Bloom's taxonomy: An overview. Theory into Practice, 41(4), 212-219. http://dx.doi.org/10.1207/s15430421tip4104_2

Krippendorff, K. (1980). Content analysis: An introduction to its methodology. Newbury Park, CA: Sage.

Lin, F. (2005). Knowledge Base of English as Second Language Teachers (Dissertation proposal). Retrieved from https://webspace.utexas.edu/cherwitz/www/ie/samples/fu-an_lin.pdf

Lin, Y. (2009). Teacher and pupil responses to a creative pedagogy_case studies of two primary classes in Taiwan (Dissertation). Retrieved from https://ore.exeter.ac.uk/repository /handle/10036/79393

Lin, Y. (2011). Fostering Creativity through Education-A Conceptual Framework of Creative Pedagogy. Creative Education, 2(3), 149-155. http://dx.doi.org/10.4236/ce.2011.23021

Ministry of Education. (2011). Integrating Higher-Order Thinking Skills (HOTS) with the Teaching of Literature. The Teachers' Handbook. Retrieved from http://baddah.org/images/books/The\%20Teachers'\%20Handbook. pdf

Razmjoo, S., \& Kazempourfard, E. (2012). On the representation of Bloom's Revised Taxonomy in Interchange Coursebooks. The Journal of Teaching Language Skills (JTLS), 4(1), 171-204. Retrieved from http://jtls.shirazu.ac.ir/article_336_0.html

Riazi, A., \& Mosalanejad, N. (2010). Evaluation of learning objectives in Iranian High-School and pre-university English Textbooks using Bloom's Taxonomy. The Electronic Journal for English as a Second Language, 13(4), 1-16. Retrieved from http://www.tesl-ej.org/wordpress/issues/volume13/ej52/ ej52a5/

Shaheen, R. (2010). Creativity and education. Creative Education, 1(3), 166-169. http://dx.doi.org/10.4236/ce.2010.13026

Sheldon, L. (1988). Evaluating ELT textbooks and materials. ELT Journal, 42(4), 237-246. http://dx.doi.org/10.1093/elt/42.4.237

Shulman, L. (1987). Knowledge and teaching: Foundations of the new reform. Harvard Educational Review, $57(1)$.

Sidek, H. (2010). An analysis of the EFL secondary reading curriculum in Malaysia: approaches to reading preparation for higher education (Dissertation). University of Pittsburgh. Retrieved from http://d-scholarship.pitt.edu/9837/1/mohdsidekharison2010.pdf

Snow, C. (2002). Reading for Understanding toward an $R \&$ D Program in Reading Comprehension. RAND, Arlington, US.

Surjosuseno, T., \& Watts, V. (1999). Using Bloom's Taxonomy to teach reading in English as a foreign language classes. QJER, 15(2), 227-244. Retrieved from http://www.iier.org.au/qjer/qjer15/ surjosuseno.html

Wagner, T. (2008). "Rigor redefined." Educational Leadership, 66(2), 20-24.

Yamin, T. (2013). Excellence, Innovation Education, and Nurturing the Gifted. The 6th International Conference on Teacher Education. Retrieved from http://www.mofet.macam.ac.il/amitim/iun/International Conference2013/program/day2/Pages/1620-1720-2.aspx

Zohar, A. (2007). Pedagogical horizons for learning. Retrieved from http://tlc.cet.ac.il/CETHandler. $a$ shx? $=$ CetEntities.FileViewer\&i=7b6c26a9-ffd0-426d-b508-19d6c9d151f1\&id=42650 
Zohar, A. (2008). Teaching thinking on a national scale: Israel's pedagogical horizons. Educational leadership. http://dx.doi.org/10.1016/j.tsc.2008.03.002

Zohar, A. (2010). A tale of two planets? Policy-making and actual classrooms: The case of teaching to think in civics education (Unpublished document). Retrieved from https://www.sss.ias.edu/files/papers/ paper40.pdf

\section{Copyrights}

Copyright for this article is retained by the author(s), with first publication rights granted to the journal.

This is an open-access article distributed under the terms and conditions of the Creative Commons Attribution license (http://creativecommons.org/licenses/by/3.0/). 